\title{
Functional characterization of WRKY46 in grape and its putative role in the interaction between grape and phylloxera (Daktulosphaira vitifoliae)
}

\author{
Feng-Pan Wang ${ }^{1,2,3}$, Pan-Pan Zhao ${ }^{2,3}$, Lei Zhang ${ }^{4}$, Heng Zhai ${ }^{1}$ and Yuan-Peng Du ${ }^{1}$
}

\begin{abstract}
WRKY transcription factors are involved in defense responses caused by biotic stresses. Phylloxera (Daktulosphaira vitifoliae Fitch), a pest widespread in viticulture, elicits transcriptional reprogramming of plant defense-associated components, such as regulons related to WRKYs and salicylic acid (SA) signaling. In this study, we characterized WRKY46, a WRKY transcription factor responsible for phylloxera attack, and revealed the molecular mechanism for WRKY-mediated defense responses to phylloxera. qRT-PCR and GUS staining analyses revealed that WRKY46 is induced in response to phylloxera damage and mechanical wounding. VVWRKY46 is a nuclear-localized transcription factor that activates its downstream target VVCHIB by direct protein-DNA interaction. Regulons involved in the SA-mediated defense response were regulated during incompatible interactions between "1103 Paulsen" rootstock and phylloxera. In addition, WRKY46 exhibited a higher transcript abundance in "1103 Paulsen" than in "Crimson Seedless", regardless of whether the plants were infected with phylloxera. Furthermore, the enhanced expression of VVWRKY46 significantly attenuated phylloxera attack and delayed nymph development of composite grape plants. In summary, we demonstrated that WRKY46 plays a role in the SA-mediated defense-regulatory network by directly binding to the downstream structural gene VVCHIB. The phylloxera-responsive gene WRKY46 was identified, which could improve the understanding of the basic mechanism of grapevine in response to phylloxera.
\end{abstract}

\section{Introduction}

Plants often face multiple biological threats in highly variable environments, so co-survival strategies offer constitutive and induced resistance against microbial pathogens and herbivores. Two well-documented immune systems, pathogen-associated molecular pattern

\footnotetext{
Correspondence: Yuan-Peng Du (duyuanpeng001@163.com)

${ }^{1}$ State Key Laboratory of Crop Biology, Key Laboratory of Biology and Genetic Improvement of Horticultural Crops (Huang-Huai Region, Ministry of

Agriculture), College of Horticulture Science and Engineering, Shandong Agricultural University, Tai-an 271000 Shandong, China

${ }^{2}$ Key Laboratory of Optoelectronic Devices and Systems of Ministry of Education and Guangdong Province, College of Optoelectronic Engineering,

Shenzhen University, Shen-zhen 518060 Guangdong, China

Full list of author information is available at the end of the article.

These authors contributed equally: Feng-Pan Wang, Pan-Pan Zhao
}

(PAMP)-triggered immunity (PTI) and effector-triggered immunity (ETI), have been reported to play important roles in plant defense responses ${ }^{1}$. PTI and ETI are innate immunities that synergistically activate plant defense responses to prevent the invasion of organisms ${ }^{2,3}$. In complex immune systems, several plant hormones, especially salicylic acid (SA), jasmonic acid (JA), and ethylene (ET), act as signaling molecules that trigger downstream defense responses ${ }^{4-6}$. Interestingly, the SA signaling pathway is often involved in biotroph-induced defense responses, while JA and ET are usually responsible for the immune response associated with necrotrophic pathogens and herbivores ${ }^{7}$. As a mobile signaling hormone, SA is able to initiate long-lasting and systemic immune responses to microbial pathogens, nematodes, aphids, and

\section{(c) The Author(s) 2019}

(c) (i) Open Access This article is licensed under a Creative Commons Attribution 4.0 International License, which permits use, sharing, adaptation, distribution and reproduction in any medium or format, as long as you give appropriate credit to the original author(s) and the source, provide a link to the Creative Commons license, and indicate if changes were made. The images or other third party material in this article are included in the article's Creative Commons license, unless indicated otherwise in a credit line to the material. If material is not included in the article's Creative Commons license and your intended use is not permitted by statutory regulation or exceeds the permitted use, you will need to obtain permission directly from the copyright holder. To view a copy of this license, visit http://creativecommons.org/licenses/by/4.0/. 
chewing-type herbivores ${ }^{8,9}$. An in-depth study of the genetic components can provide an improved understanding of the fine mechanisms of SA-mediated immune regulatory networks ${ }^{10}$. Stylet-feeding pests such as aphids, whiteflies, thrips, and parasitic nematodes can induce SAmediated plant defense responses via mechanical damage and salivation ${ }^{4,5}$. Moreover, infestation of silverleaf whiteflies can cause local and systemic accumulation of SA-responsive genes in Arabidopsis ${ }^{4}$. In addition, expression profiling revealed that SA-inducible genes are activated when plants are under attack by phloem-feeding insects and nematodes ${ }^{5}$.

In the ETI defense response, Resistance (R) genes are critical for the perception and recognition of effectors delivered by the corresponding pathogens ${ }^{11,12}$. A previous study reported that when SA was abnormally degraded to catechol, tomato plants carrying Mi-1 lost partial resistance to parasitic nematodes, and exogenous applications of an SA analog completely restored the resistance ${ }^{13}$. Furthermore, with upregulated pathogenesis-related (PR) genes, tomato pretreated with SA is highly resistant to root-knot nematode juveniles ${ }^{14}$. Studies conducted by $\mathrm{Du}$ et al. ${ }^{15}$ and Elhamahmy et al. ${ }^{16}$ confirmed the positive effects of SA applications on reducing pest population densities among crop plants. In addition to $\mathrm{R}$ genes, a large number of defense-related components are known to be involved in SA-mediated plant immune-regulatory networks, particularly the transcription factor WRKY. Previously, WRKY transcription factors were reported to act as multilevel regulators of plant defense responses to phytopathogenic organisms ${ }^{17}$. For example, overexpression of OsWRKY89 results in increased levels of SA and increased resistance to white-backed plant hoppers ${ }^{18}$. Similarly, a chrysanthemum WRKY transcription factor, CmWRKY48, inhibits the growth of aphids in stable overexpression plants ${ }^{19}$. In contrast, nematodes were found to thrive in host plants (tomato and Arabidopsis) when S1WRKY45 and AtWRKY23 appeared to be hijacked $^{20,21}$. However, there is limited information on how WRKYs modulate the SA-mediated defense signaling cascade.

A report by Verk et $\mathrm{al}^{22}$ provided additional evidence that AtWRKY28 and AtWRKY46 act as upstream regulators of SA metabolism, directly binding to the W-box (C/TTGAC/T) within the ICS1 and PBS3 promoters. In addition to SA biosynthesis, WRKY transcription factors are involved in interactions with other defense-related elements. Mitogen-activated protein kinases (MAPKs) posttranslationally phosphorylate pathogen-induced WRKY proteins to modulate SA-mediated immune responses $^{23}$. In addition, WRKY33 is involved in the synthesis of antimicrobial camalexin by targeting the promoter of PHYTOALEXIN DEFICIENT3 $(P A D 3)^{24}$. The Arabidopsis Nonexpressor of PR gene 1 (NPR1) is essential for the correct induction of PRs in the NPR1dependent defense response ${ }^{25}$. Yu et al. ${ }^{26}$ confirmed that certain WRKY genes act upstream of NPR1, whereas Wang et $\mathrm{al}^{27}$ and Kim et al. ${ }^{28}$ documented that NRP1 directly affects the expression of WRKY genes in SAmediated defense responses, suggesting a multilevel regulation of WRKY genes during plant defense responses. In addition, WRKYs can act as direct regulators of PRs independently of NRP1 or other components ${ }^{29}$.

Grape phylloxera is a worldwide pest that feeds only on Euvitis subgenera species. This insect feeds on the roots of susceptible grape (Vitis spp.) cultivars, leading to the formation of root galls called nodosities ${ }^{30}$. However, there is limited literature on the biological and molecular interaction between phylloxera and its grapevine host. In the phylloxera-resistant rootstock "Borner", phylloxera attack alters the transcript abundance of genes that are related to the defense response, genes that encode hypersensitive response (HR) proteins, genes involved in the biosynthesis of phytoalexins, and genes that encode transcription factors ${ }^{31,32}$. In fact, preliminary GeneChip assays revealed that phylloxera infestation significantly affected the expression levels of WRKY genes in different grapevine genotypes ${ }^{15}$.

In this study, the grape WRKY gene VvWRKY46 was induced by phylloxera infestation on plants of the cultivar "Crimson Seedless" and of the rootstock "1103 Paulsen". Further investigation revealed that WRKY46 is involved in the SA-mediated immune response by targeting downstream defense-associated genes.

\section{Materials and methods}

\section{Plant materials and phylloxera}

The table grape cultivar "Crimson Seedless" (C133-199 $\mathrm{x}$ Emperor) and the rootstock "1103 Paulsen" (1103P, Vitis berlandieri $\mathrm{x}$ Vitis rupestris) were used in this study. "Crimson Seedless" is susceptible to phylloxera, while $1103 \mathrm{P}$ is mildly resistant. All plants were cultivated in vitro on 1/2-strength MS solid media with half the amount of macronutrients; the media were supplemented with $20 \mathrm{~g} / \mathrm{L}$ of sucrose, $7.0 \mathrm{~g} / \mathrm{L}$ of agar powder, and $0.2 \mathrm{mg} / \mathrm{L}$ of the phytohormone IBA. The plants were grown at $25^{\circ} \mathrm{C} / 20^{\circ} \mathrm{C}$ under a $16 \mathrm{~h} / 8 \mathrm{~h}$ (light/dark) photoperiod. Shoot cuttings with a minimum of one bud and leaf were used for monthly subcultures. Well-rooted plantlets were transplanted into plastic pots $(10.5 \mathrm{~cm}$ height $\times 10.5 \mathrm{~cm}$ diameter) filled with a mixture of $50 \%$ peat and $50 \%$ perlite. The pots were subsequently covered with plastic bags for 1 week and then incubated under constant conditions of $25^{\circ} \mathrm{C} / 20^{\circ} \mathrm{C}$ and a $16 \mathrm{~h} / 8 \mathrm{~h}$ (light/ dark) photoperiod.

Five-year-old self-rooted grapevine plants (Crimson Seedless) were used to determine the tissue-specific expression of $V v W R K Y 46$. Different tissues were 
collected in the 2016 growing season and immediately frozen in liquid nitrogen; at least three biological replicates were included. Whole fruit were sampled at 4 weeks after fruit set. The fruit skin and pulp were dissected from the harvested fruit.

Arabidopsis ecotype Columbia (Col) seedlings were transplanted into square pots filled with peat and vermiculite $(1: 1, \mathrm{v} / \mathrm{v})$ in a growth chamber maintained at $20^{\circ} \mathrm{C} /$ $18^{\circ} \mathrm{C}$ and with a $10 \mathrm{~h} / 14 \mathrm{~h}$ (light/dark) photoperiod.

Excised tertiary roots of the cultivar "Kyoho" ["Campbell Early" $(4 \times) \times$ "Centennial"] were used to rear phylloxera (Daktulosphaira vitifoliae) as described by Granett et al. ${ }^{33}$. To collect nymphs for inoculation, the phylloxera insects were reared in Petri dishes as described previously by Granett et al. ${ }^{33}$. The incubator was strictly sealed using parafilm to prevent any phylloxera from escaping.

\section{Obtaining transgenic grape roots}

Shoot cuttings of grape plantlets with a minimum of two buds and leaves were prepared for infection under aseptic conditions. Agrobacterium rhizogenes strain C58C1 harboring the 35S:VvWRKY46-GFP plasmid was freshly grown on resistant plates at $28^{\circ} \mathrm{C}$ for 2 days (d). A $20 \mathrm{-ml}$ culture of liquid broth containing kanamycin $(50 \mathrm{mg} / \mathrm{L})$ and rifampicin $(20 \mathrm{mg} / \mathrm{L})$ was inoculated with the above $A$. rhizogenes and incubated at $28^{\circ} \mathrm{C}$ overnight with shaking at $150 \mathrm{rpm}$. The bacterial cells were collected and then resuspended to $A_{600}=1.0$ using sterilized 1/2strength MS liquid media containing $100 \mu \mathrm{M}$ acetosyringone. A. rhizogenes infection was carried out in a 250- $\mathrm{ml}$ conical flask, in which the shoot cuttings were submerged in the resuspension in the dark, in which and the conical flask was shaken at $100 \mathrm{rpm}$ at $25^{\circ} \mathrm{C}$ for $15 \mathrm{~min}$. The shoot cuttings were then blotted with sterile filter paper to remove excess Agrobacterium and subsequently inserted into solid rooting media (1/2-strength MS medium, $20 \mathrm{~g} / \mathrm{L}$ of sucrose, $7.0 \mathrm{~g} / \mathrm{L}$ of agar powder, $200 \mathrm{mg} / \mathrm{L}$ of cefotaxime, and $0.2 \mathrm{mg} / \mathrm{L}$ of IBA). Independent regenerative roots were induced around the wounds of shoot cuttings at 4-7 weeks after infection. The transgenic roots were subjected to light at $480 \mathrm{~nm}$ when they were $\sim 3 \mathrm{~cm}$ in length, and the transgenic and nontransgenic roots were discerned according to green fluorescence.

\section{Phylloxera inoculation}

A stereomicroscope (Olympus, Japan) and a small artist's brush were used to collect 1st-instar or 2nd-instar phylloxera nymphs on a piece of filter paper $(5 \mathrm{~cm}$ diameter). There were 50-60 nymphs on each filter paper. The filter paper was soaked with sterile water to prevent nymphs from escaping. The plantlets that had been previously transplanted into pots for four to 6 weeks were inoculated using the newly collected young nymphs according to the method described by Granett et al. ${ }^{33}$. To inoculate young grape roots with the nymphs, whole roots were removed from the pots, taking care to avoid harming them. Four to five pieces of filter paper that harbored phylloxera nymphs were used to wrap the young roots, and the paper was affixed by winding them with a thin thread. The inoculated roots were put into pots and covered with moistened vermiculite. The roots of each inoculated plantlet were examined using a stereomicroscope to confirm the formation of the feeding site. According to the time course assay indicated, young phylloxera-injured roots were sampled, and the samples were frozen in liquid nitrogen and stored at $-80^{\circ} \mathrm{C}$. Accordingly, the young roots of control plants were treated using a fine needle mimicking the puncture of the nymph stylet with the help of a stereomicroscope. The mechanically wounded young roots were wrapped with filter paper that was not exposed to nymphs and put into the pots, after which they were covered with moistened vermiculite. The control plants were sampled by collecting young wounded roots in accordance with the time course. The treatments corresponding to each time point included three independent biological replicates.

To investigate the mRNA level of WRKY46 in grape roots after nodosity formation, several inoculated plants were incubated under normal conditions of $25^{\circ} \mathrm{C} / 20^{\circ} \mathrm{C}$ with a $16 \mathrm{~h} / 8 \mathrm{~h}$ (light/dark) photoperiod. One month later, the nodosities and healthy roots were collected and kept in liquid nitrogen. Roots harvested from noninoculated plants were used as controls. Each sample had at least three biological replicates.

To evaluate the effects of SA and Me-JA on phylloxera, the tertiary grape roots that were sampled from 5 -year-old "Crimson Seedless" were divided into 5 - $\mathrm{cm}$ pieces. Both sides of the root segments were wrapped in absorbent cotton to avoid desiccation. The root pieces were then put into Petri dishes $\left(9 \mathrm{~cm}\right.$ in diameter) in an incubator at $25^{\circ}$ C. Before inoculation with phylloxera nymphs, SA (0.1 mM, Sigma, USA) and Me-JA (1 mM, Sigma, USA) solutions were used to moisten the absorbent cotton. Sterile water was used as the moistening agent for the mock control treatment. Each root was inoculated with 100 nymphs, which were placed on the root surface. The number of feeding nymphs was then measured 10 days post inoculation.

To evaluate the susceptibility of transgenic roots produced from "Crimson Seedless" shoot cuttings, $\sim 50$ phylloxera eggs (5 days post oviposition) were prepared to inoculate each composite plant as described by Kellow et al. ${ }^{34}$. Before inoculation, transgenic roots were distinguished by tying thin threads after fluorescence detection. The inoculated composite plants were put into glass bottles and incubated under constant conditions of $25^{\circ} \mathrm{C}$ in the dark. One week later, the numbers of 
phylloxera nymphs that infested successfully were calculated per root using a stereomicroscope (Olympus, Japan).

\section{The total RNA extraction, qRT-PCR, and semiquantitative RT-PCR}

Plant RNA was extracted via a previously described modified method ${ }^{35}$. The total RNA was quantified with a microspectrophotometer ND2000C (Thermo, USA) set to different wavelengths. RNA integrity was confirmed using $1 \%$ agarose gel electrophoresis. Approximately $1 \mu \mathrm{g}$ of the total RNA was then used for first-stand cDNA synthesis using a PrimeScript ${ }^{\mathrm{TM}}$ RT Reagent Kit with gDNA Eraser following the manufacturer's protocol (TaKaRa, Japan). For qRT-PCR analysis, a stock solution of the first-stand cDNA was diluted 20-40 times with sterilized $\mathrm{dd}_{2} \mathrm{O}$. qRT-PCR was then conducted in a 96-well plate using Real Time PCR instrument (Life Technologies, USA). Each well contained a $20 \mu \mathrm{L}$ of reaction volume consisting of $1 \mu \mathrm{L}$ of diluted cDNA, $10 \mu \mathrm{L}$ of Ultra SYBR Mixture (CWBIO, China), $0.5 \mu \mathrm{L}+0.5 \mu \mathrm{L}$ of gene-specific primers $(10 \mathrm{mM})$, and $8 \mu \mathrm{L}$ of sterilized $\mathrm{ddH}_{2} \mathrm{O}$. The PCR amplification procedure was as follows: initial denaturation at $95^{\circ} \mathrm{C}$ for $10 \mathrm{~min}$, followed by 40 cycles of $95^{\circ} \mathrm{C}$ for $10 \mathrm{~s}$ and $60^{\circ} \mathrm{C}$ for $30 \mathrm{~s}$. The specificity of the PCR products was confirmed by dissociation melting curve analysis. The housekeeping genes Vvactin and AtGAPDH were used as internal references for grape and Arabidopsis, respectively. The values of transcript abundance were calculated using the $2^{-\triangle \triangle \mathrm{Ct}}$ method.

For semiquantitative RT-PCR analysis, gene-specific primers were employed for PCR amplification in a $20 \mu \mathrm{L}$ reaction volume consisting of $1 \mu \mathrm{L}$ of cDNA stock solution, $10 \mu \mathrm{L}$ of $2 \mathrm{x}$ EasyTaq PCR Super Mix, $0.5 \mu \mathrm{L}$ each of the forward and reverse primers, and $8 \mu \mathrm{L}$ of $\mathrm{ddd}_{2} \mathrm{O}$. The reaction tubes were then subjected to the following cycling procedure: preincubation at $94{ }^{\circ} \mathrm{C}$ for $10 \mathrm{~min}$, followed by $25-35$ cycles at $94{ }^{\circ} \mathrm{C}$ for $30 \mathrm{~s}, 58^{\circ} \mathrm{C}$ for $30 \mathrm{~s}$, and $72{ }^{\circ} \mathrm{C}$ for $30 \mathrm{~s}$. The housekeeping gene Vvactin was used as an internal control. Finally, all PCR products were separated on $1 \%$ agarose gels and detected via a DNA imaging analysis system. Three independent biological assays were conducted to ensure identical results. The gene-specific primer pairs were synthesized by GENEWIZ (Suzhou city, China) and are listed in the Supplemental Files.

\section{Plastid construction and Arabidopsis transformation}

Standard molecular biology techniques and the incision enzyme system (TaKaRa, Japan) were used for gene cloning and plasmid construction. Grape genomic DNA and first-stand cDNA were used as templates for PCR amplification of the promoter and full-length coding sequences, respectively. The open-reading frame (ORF) of $V v W R K Y 46$ was inserted upstream of the green fluorescent protein (GFP) driven by the cauliflower mosaic virus $35 \mathrm{~S}$ promoter (CaMV35S). The promoter sequences of $V v W R K Y 46$ and $V v C H I B$ were subcloned into the upstream region of the reporter gene $\beta$-glucuronidase (GUS). In addition, the reporter vector p1300-GN was modified by introducing a fragment of the 3 -terminus of the $35 \mathrm{~S}$ promoter into the upstream region of the GUS gene, and the vector was termed mini35S: GUS. A double-stranded DNA fragment consisting of two tandem W-box motifs that were derived from the PBS3 promoter was synthesized and inserted into the upstream region of mini35S. In the mutant reporter construct mWbox-mini35S:GUS, the core sequence TGAC of two tandem W-box motifs was replaced with AGAC, and then the double-stranded DNA fragment with mutated W-box motifs was inserted into the upstream region of mini35S. All primers used for plasmid construction are listed in the Supplemental files. Before transforming the mutant reporter construct into plant materials, the above vectors were individually transformed into Agrobacterium tumefaciens strain LBA4404.

To obtain stable transgenic Arabidopsis lines, the constructs 35S:VvWRKY46-GFP and $\mathrm{p} V v$ WRKY46:GUS were transformed into Col-0 Arabidopsis via the A. tumefaciens-mediated floral dip method. The resultant T0 seedlings were screened on resistant media that contained the corresponding antibiotic and confirmed via qRT-PCR. T3 homozygous transgenic lines were used for experiments.

\section{Subcellular localization}

The overexpression vector 35S:VvWRKY46-GFP was used to carry out subcellular localization experiments. This in-fusion vector was transformed into A. tumefaciens strain GV3101 harboring the p19 helper plasmid. Square $(1 \mathrm{~cm})$ onion epidermal cells were cut from fresh onion bulbs and immediately submerged into a suspension of $A$. tumefaciens at $\mathrm{OD} 600=0.8$. After incubating for $15-20 \mathrm{~min}$ at $28^{\circ} \mathrm{C}$, the onion epidermal cells were removed from the suspension, and the excess Agrobacterium solution was blotted using dry filter papers. Infected epidermal cells were coincubated on MS media (containing $20 \mathrm{~g} / \mathrm{L}$ sucrose, $100 \mu \mathrm{M}$ acetosyringone, and $0.7 \%$ agar powder) for 3 days in the dark at $22^{\circ} \mathrm{C}$. A $35 \mathrm{~S}$ : GFP blank vector was used as a positive control. GFP was detected by laser confocal microscopy at the proper excitation wavelength.

\section{Yeast one-hybrid assays}

A yeast one-hybrid assay was performed to determine the binding activity of VvWRKY46 to the W-box motif and its putative target genes in yeast strain Y187. Doublestranded DNA fragments that consisted of two W-box motifs or their mutants were synthesized and introduced 
into the upstream region of the mini-promoter of HIS3, which were termed W-box-pHIS2 and mWbox-pHIS2, respectively. Grape genomic DNA was used to amplify the promoter sequences of $V \nu C H I B, V \nu C H I B 1$, and $V v G 1$ in construction of the reporter vectors. The full-length coding sequence of VvWRKY46 was cloned from cDNA and inserted into the effector construct pGADT7. The effector construct pGADT7-VvWRKY46 together with the reporter vector were co-transformed into yeast cells according to the protocol provided by Clontech (TaKaRa, Japan). A pHIS2 empty vector served as a negative bait. The transformed yeast cells were screened on the selective DO medium plates [tryptophan (Trp) and leucine (Leu)deficient, SD-T/-L]. Positive transformants were also verified by PCR amplification using gene-specific primers. Finally, the binding activity of VvWRKY46 to the W-box motifs or its target genes was tested on a selective DO medium plate [Trp, Leu, and histidine (His)-deficient, SD$\mathrm{T} / \mathrm{-L} / \mathrm{-H}$ ] supplemented with 3-aminotriazole (3-at; Solarbio) at $20 \mathrm{mM}$.

\section{Transient expression assays}

Unexpanded leaves of grapevine ( $V$. vinifera $\mathrm{L}$. var. Cabernet Sauvignon) were collected during the growing season for transient expression assays. All effector and reporter constructs were transferred into A. tumefaciens strain GV3101 harboring a p19 helper vector. The Agrobacterium strain harboring individual constructs was incubated to an optical density of OD600 $=2-3$, harvested by centrifugation at $5000 \mathrm{rpm}$ for $5 \mathrm{~min}$, and then washed with sterile water. Each strain was resuspended in inoculation buffer (10 mM MES, $2 \%$ sucrose, $0.2 \mathrm{mM}$ acetosyringone, and $100 \mathrm{mM} \mathrm{MgCl} 2$ ), and mixed as indicated to the same concentration $(\mathrm{OD} 600=1.0)$. The grape leaves were submerged in the suspension under negative pressure conditions $(0.085 \mathrm{MPa})$ in a vacuum. The vacuum infiltration was applied for $8 \mathrm{~min}$, followed by recovery for $5 \mathrm{~min}$; this cycle was repeated three times until the leaves sank at one bar of pressure. After removing excess suspension with filter papers, the grape leaves were placed on moistened cotton in Petri dishes to avoid dehydration. The leaves were inoculated at $25^{\circ} \mathrm{C}$ in the dark for $12 \mathrm{~h}$ before being transferred to normal conditions. All the leaves were subjected to histochemical staining 3 days later.

\section{Histochemical GUS analysis}

The sampled grapevine leaves were fully immersed in staining buffer in a $100-\mathrm{mL}$ conical flask, and then the flask was sealed and stored for $12 \mathrm{~h}$ in the dark at $37^{\circ} \mathrm{C}$. The staining buffer consisted of $0.5 \mathrm{mg} / \mathrm{mL}$ X-Gluc (5bromo-4-chloro-3-indolyl- $\beta$-d-glucuronide), $\quad 100 \mathrm{mM}$ phosphate buffer ( $\mathrm{pH}=7.0), 0.01 \%$ Triton $\mathrm{X}-100,10 \mathrm{mM}$ EDTANa $_{2}, 0.5 \mathrm{mM} \mathrm{K} \mathrm{K}_{4} \mathrm{Fe}(\mathrm{CN})_{6}$, and $0.5 \mathrm{mM} \mathrm{K} \mathrm{K}_{3} \mathrm{Fe}(\mathrm{CN})_{6}$.
After incubation, the reaction buffer was replaced with $75 \%(\mathrm{v} / \mathrm{v})$ ethyl alcohol to decolorize the chlorophyll. Finally, the fully decolorized leaves were imaged to record the $\beta$-D-glucuronidase activity.

\section{Electrophoretic mobility shift assays (EMSAs)}

To obtain recombinant proteins, the full-length coding sequence of VvWRKY46 was amplified via PCR from cDNA and introduced into a pET32a vector at the BamHI and Sall restriction sites. The Escherichia coli BL21 (DE3) strain that harbored the above construct was incubated in LB liquid media to a concentration of OD600 $=0.5$. After the addition of $1 \mathrm{mM}$ isopropyl thio- $\beta$-D-galactoside (IPTG), the recombinant protein of interest was induced at $16^{\circ} \mathrm{C}$ or $37^{\circ} \mathrm{C}$ for $6 \mathrm{~h}$. The crude protein extracts were then purified using a His-tagged Protein Purification Kit according to the protocol provided by the manufacturer (His-tag, CWBIO, China), and were later used for EMSAs. Three single-stranded DNA fragments that included putative W-boxes and their complementary chains were synthesized by GENEWIZ (Suzhou city, China). Each single-stranded DNA was then labeled with biotin using an EMSA Probe Biotin Labeling Kit (Beyotime, China). The reverse complementary single-stranded oligonucleotides were equally mixed and annealed using a thermal cycler (Thermo, USA) to form double-stranded DNA according to the temperature-gradient descent strategy. Wild-type and mutated DNA probes without biotin labeling served as competitors. All the primers used in this assay are listed in Table S1.

The binding reaction mixtures contained $1 \mathrm{mg}$ of purified recombinant protein and $1 \mu \mathrm{L}$ of $10 \times$ gel shift binding buffer ( $50 \%$ glycerol, $50 \mathrm{mM} \mathrm{MgCl}_{2}, 5 \mathrm{mM}$ EDTA, $10 \mathrm{mM}$ DTT, $500 \mathrm{mM} \mathrm{KCl}, 250 \mathrm{mM}$ HEPES, $\mathrm{pH}$ 7.4) in a total volume of $10 \mu \mathrm{L}$. One microliter $(0.05 \mu \mathrm{M})$ of biotinlabeled probe was incubated with the above components for $20 \mathrm{~min}$ at $24{ }^{\circ} \mathrm{C}$. For the competition assay, the HIStagged protein together with the binding reaction was preincubated with an unlabeled or mutated probe for $20 \mathrm{~min}$ at $24^{\circ} \mathrm{C}$ and then mixed with labeled probes for another $20 \mathrm{~min}$. After incubation, each sample was resolved on $6 \%$ native acrylamide gels in $0.5 \times \mathrm{TBE}$ buffer (44.5 mM Tris-base, $44.5 \mathrm{mM}$ boric acid, $1 \mathrm{mM}$ EDTA) for $1-2 \mathrm{~h}$ at $100 \mathrm{~V}$. The gel was transferred to a nylon membrane (Positively CHGD Nylon Transfer Membrane, GE Healthcare, UK) for chemiluminescent detection using a LightShift $^{\mathrm{TM}}$ chemiluminescent EMSA Kit (Thermo, USA) according to the manufacturer's protocol.

\section{Results \\ Expression of WRKY46 is rapidly induced by phylloxera attack and wounding}

The genome-wide expression profile of the grape WRKY transcription factor genes in response to 
phylloxera infestation was investigated for the phylloxerasusceptible cultivar "Crimson Seedless" as well as the phylloxera-resistant rootstock 1103P. The changes in the transcript abundance of the grape WRKY transcription factor genes of both genotypes revealed their putative involvement in the interactions between grape and phylloxera (Fig. 1a, b). The transcript levels of $V v W R K Y 33$ (VIT_208s0058g00690), 41 (VIT_202s0025g01280), 45 (VIT_214s0068g01770), 46 (VIT_215s0046g01140), and 72 (VIT_201s0026g01730) in "Crimson Seedless" increased and peaked at $24 \mathrm{~h}$, with an abrupt decrease in the subsequent $48 \mathrm{~h}$ after inoculation (Fig. S1). However, the mRNA levels of above WRKY genes continuously increased at $48 \mathrm{~h}$ after inoculation (Fig. S2). Therefore, it is confirmed that the grape WRKY genes are widely involved in the interaction between phylloxera and its host species (Fig. 1a, b).

To explore how and at what level $V \nu W R K Y \mathrm{~s}$ are associated with the innate immunity of grape phylloxera feeding damage, we conducted an in-depth study on the phylloxera-induced WRKY gene, VvWRKY46, to determine its role in the defense response. First, a time course assay was performed to determine the transcription level of WRKY46 in the roots in the early stages of phylloxera attack. $V \nu W R K Y 46$ was significantly upregulated in response to stimulated mock stylet puncture and phylloxera infestation in "Crimson Seedless" (Fig. 2a). Second, phylloxera attack resulted in a stronger and delayed increase in VvWRKY46 mRNA levels compared with mechanical wounding. Therefore, we speculate that both mechanical and chemical stimuli in turn promote the activation of $V v W R K Y 46$ expression, and that stylet secretions may play a leading role in the phylloxera-grape interaction. In addition, we also studied the expression pattern of WRKY46 in partially incompatible interactions between phylloxera and "1103 Paulsen" (1103P) rootstock $^{36}$. Similar results were obtained as excepted (Fig. 2b), which demonstrates the conserved role of WRKY46 in response to phylloxera attack in different host plants. However, phylloxera-induced upregulation of WRKY46
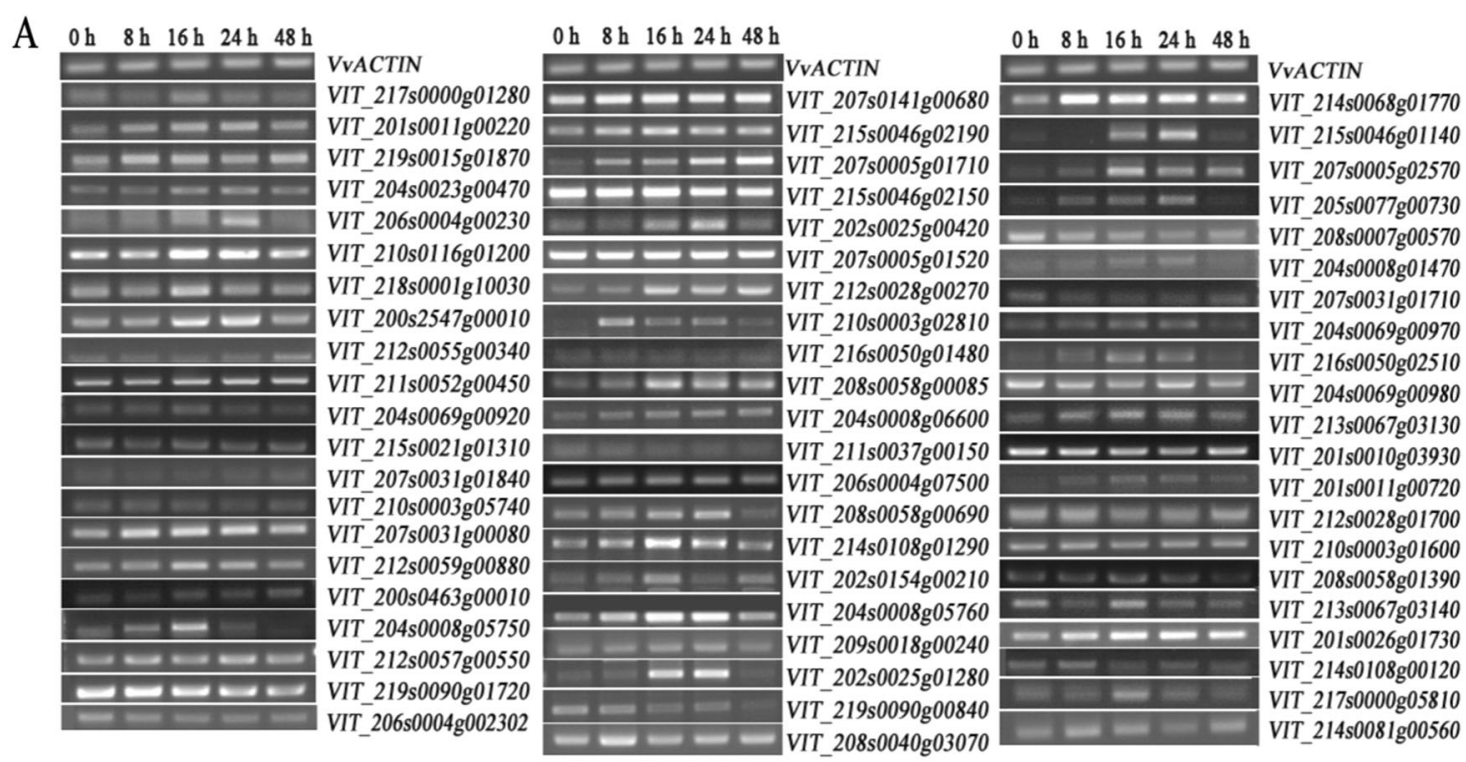

B
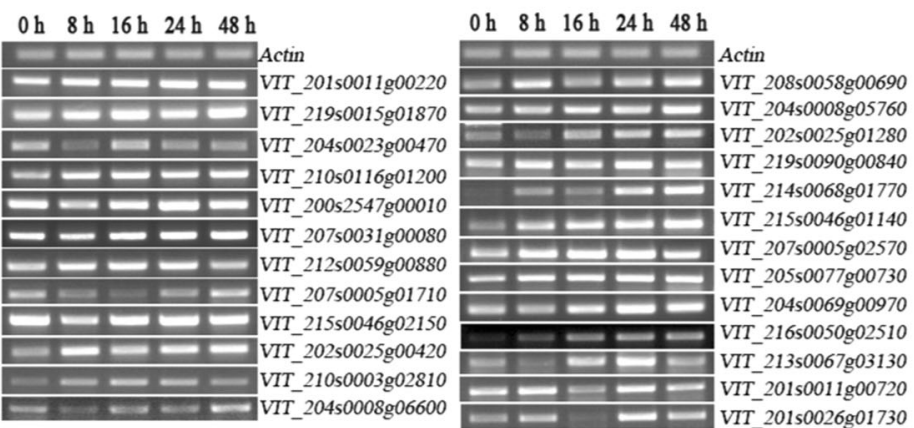

Fig. 1 The transcript abundance of grape WRKY genes in roots of "Crimson Seedless" grape and rootstock 1103P caused by phylloxera attack according to semiquantitative RT-PCR. VVActin is used as an internal standard 

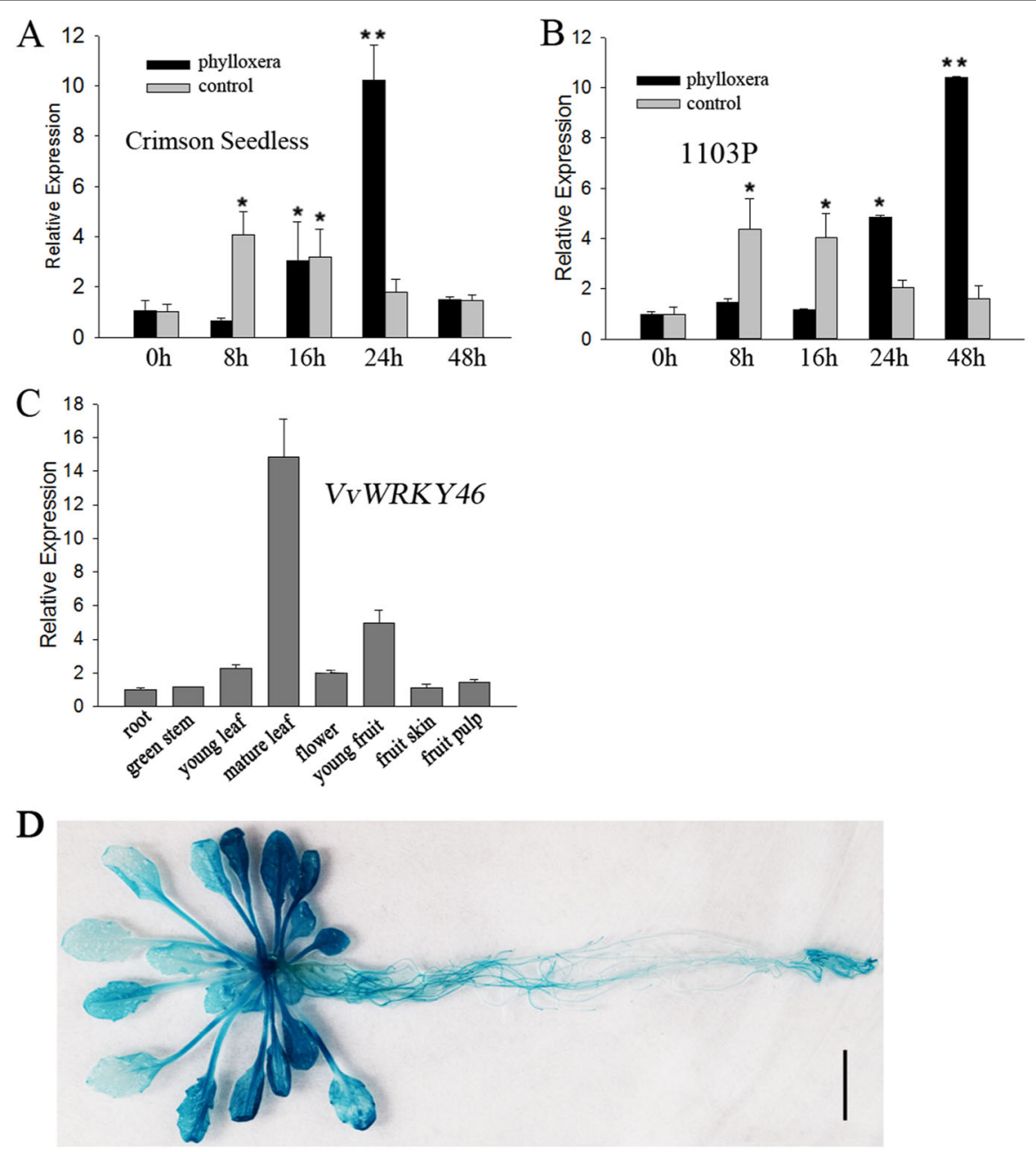

Fig. 2 Expression pattern of WRKY46 in response to phylloxera attack and wounding. $\mathbf{a}$, $\mathbf{b}$ The time course of transcription levels of WRKY46 in "Crimson Seedless" (a) and $1103 \mathrm{P}$ (b) grape roots after being inoculated with phylloxera nymphs. The gene expression was normalized to the $0 \mathrm{~h}$ expression level, which was assigned a value of 1. c Tissue-specific expression patterns of VWWRKY46 in "Crimson Seedless". The data are shown as the averages of three biological replicates + SDs. d GUS gene initiated by the endogenous promoter of VvWRKY46 expressed in transgenic Arabidopsis under normal conditions. Bar $=1 \mathrm{~cm}$

reached its maximum at $48 \mathrm{~h}$ post inoculation (hpi) in 1103P, suggesting a distinct defense response to phylloxera in resistant host plants.

To determine whether WRKY46 is specifically expressed in grape leaves and roots naturally infested by phylloxera, transcript levels in different tissues of the grapevine cultivar "Crimson Seedless" were screened. As shown in Fig. 2c, VvWRKY46 is ubiquitously expressed in all-studied organs, and has the highest level in mature leaves. To further determine the potential role of $V v W R K Y 46$ in vegetative organs, transgenic Arabidopsis plants expressing the GUS reporter gene driven by the $V v W R K Y 46$ endogenous promoter were obtained. VvWRKY46 was constitutively expressed in different organs of Arabidopsis according to tissue-specific expression profiles in grape (Fig. 2d; Fig. S3A-F). The accumulation of GUS protein indicated that $V v$ WRKY46 may be highly correlated with senescent leaves (Fig. 2d), root hairs, root tips, the pericycle (Fig. S3A, F), lateral root initiation (Fig. S3A), leaf trichomes (Fig. S3E), and abscission zones (Fig. S3B, D). Interestingly, mechanical injury significantly elicited $V v$ WRKY46 expression around the wound (Fig. S4A-C), which is consistent with the upregulation of the transcript levels.

\section{Subcellular localization and transcriptional activity of VvWRKY46}

To determine the subcellular location of VvWRKY46, the full-length coding sequence was amplified via PCR and then fused to GFP driven by the cauliflower mosaic virus (CaMV) 35S promoter. The fusion constructs were then transformed into onion epidermal cells via $A$. 


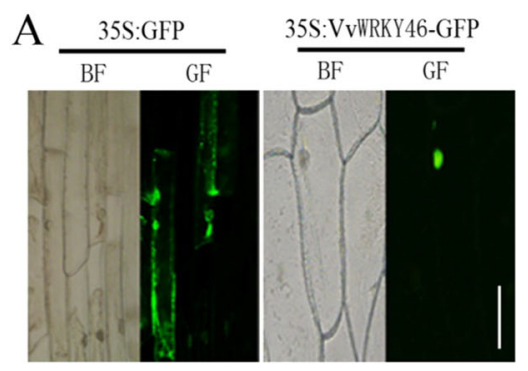

B

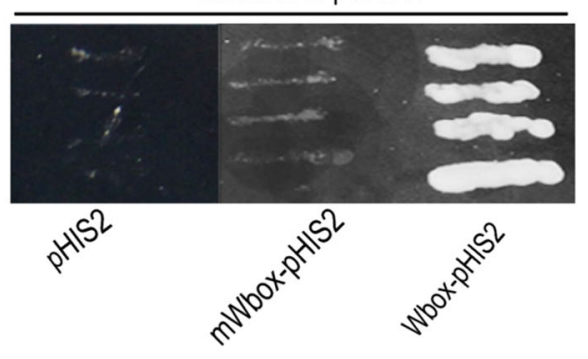

C Effector construct

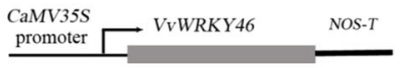

Reporter constructs

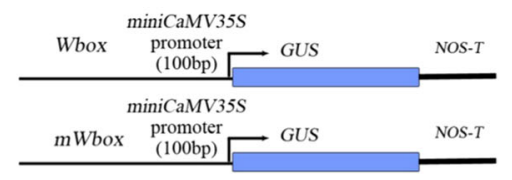

$\mathrm{D}$
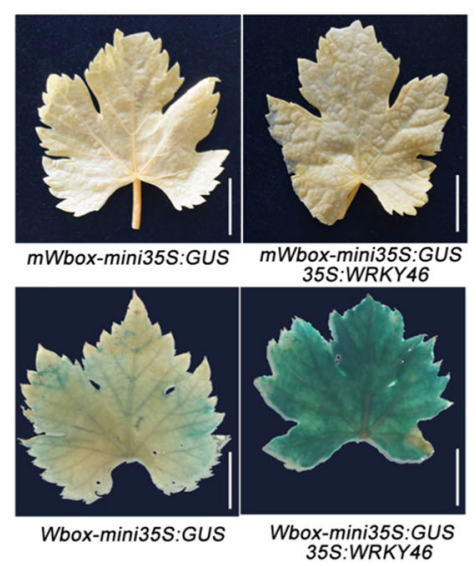

Fig. 3 Subcellular localization and transcriptional activity of VvWRKY46. a VvWRKY46 was specifically localized in the nucleus of onion epidermal cells. $\mathbf{b}$ The growth phenotype of the cotransformant that harbored PGADT7-VvWRKY46 and bait vectors on a selective DO medium plate (SD-T/-L/-H) containing $20 \mathrm{mM} 3$-aminotriazole (3-at). c Schematic diagrams of the reporter and effector constructs used for transient expression of grape leaves via A. tumefaciens. W-box and mWbox motifs were inserted upstream of the mini35S promoter to initiate the GUS gene. $\mathbf{d}$ The GUS gene was differentially expressed in grape leaves transformed with the indicated vectors. The staining level represents the abundance of GUS protein in the leaves. Bars $=100 \mu \mathrm{m}$ in (A), $1 \mathrm{~cm}$ in (d)

tumefaciens. As shown in Fig. 3a, VvWRKY46-GFP fusion proteins were exclusively located in the nucleus, while the empty vector 35S:GFP was transiently expressed throughout the nucleus and cytoplasm. WRKY transcription factors are characterized by their common binding activity to the promoter sequence TTGACC/T, which is named the W-box cis-element ${ }^{37}$. AtWRKY46 has previously been reported to act as a positive regulator of PBS3, which regulates SA biosynthesis in Arabidopsis ${ }^{22}$, and the promoter sequence of $P B S 3$ contains W-box motifs (A/TTGACT). Thus, a tandem DNA fragment consisting of two W-box motifs, ATGACT and TTGACT, was synthesized and used to determine the transcriptional activity of VvWRKY46. In the yeast one-hybrid $(\mathrm{Y} 1 \mathrm{H})$ assay, cotransformants carrying VvWRKY46-pGADT7 and the W-box-pHIS2 vectors grew on SD/-Trp-HisLeu plates (Fig. 3b). However, when the W-box sequences were mutated to AaGACT or TaGACT, the yeast cells could not grow, which is similar to the results of the blank vector (Fig. 3b). Furthermore, a homologous expression assay involving $A$. tumefaciens was performed using the constructs shown in Fig. 3c. Finally, expression of the GUS gene driven by tandem W-box motifs was significantly elicited by VvWRKY46 in grape leaves (Fig. 3d), suggesting that VvWRKY46 may transcriptionally activate downstream target genes.

\section{Phylloxera attack triggers SA-mediated defense responses in grape roots}

Innate immune responses occur locally and systemically in host grape plants in response to phylloxera feeding damage ${ }^{15,38}$. To assess the involvement of SA and JA signaling pathways in the phylloxera-grape interaction, a variety of related genes were screened for their transcript levels. The semiquantitative RT-PCR results indicated that JA-related molecular components did not show significant changes at the mRNA level in "Crimson Seedless" roots exposed to phylloxera infection (Fig. 4a). Interestingly, phylloxera attack also transcriptionally reprogrammed JA-related defense genes in partially incompatible interactions (Fig. 4b), and the expression of most of the detected genes were downregulated, except that of $V v A O C 4, V v O P R 2$, and $V \nu O P R 3$, which are involved in JA synthesis. In contrast, several SA-related defensive genes, such as $V v N P R 1, V v G 1$, and $V v P R 1$, experienced transient and slight upregulation in the time course analysis (Fig. 4c). Phylloxera infection caused a strong defense response involving the SA-related 


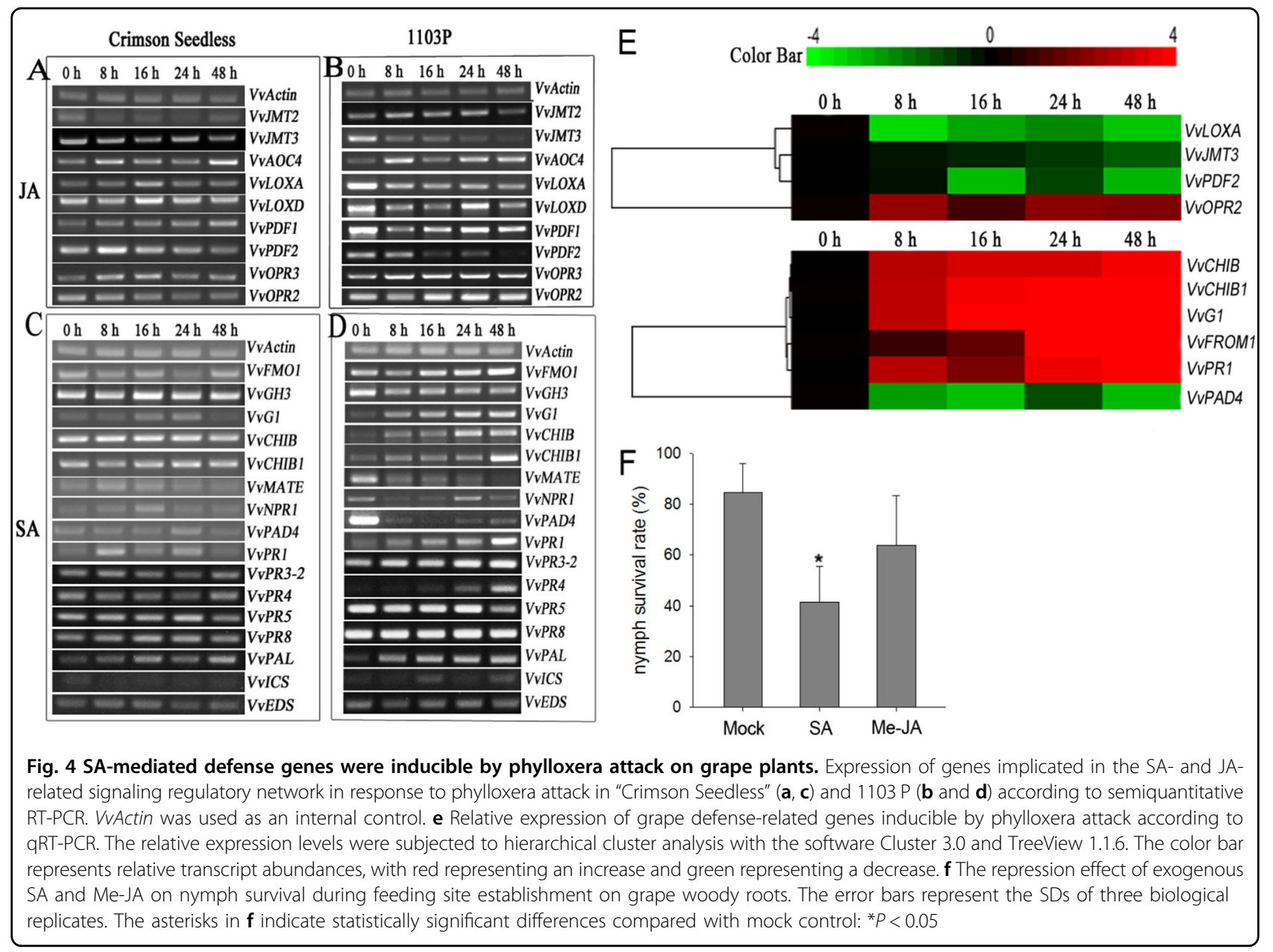

signaling pathway in the resistant host plant 1103P (Fig. $4 \mathrm{~d})$. Moreover, a large number of $P R$ genes ( $V \nu G 1$, $V \nu C H I B, V v C H I B 1, V v P R 1, V v P R 4$, and $V v P R 3.2)$ were significantly induced, implying activation of the defense response. Other SA-related genes showed unexpected expression patterns, particularly $V v G H 3$ and $V v N P R 1$, which were downregulated. We hypothesized that WRKY46 may be involved in SA-inducible and NPR1independent defense responses. To confirm the above results, qRT-PCR assays were performed, and similar results were obtained (Fig. 4e).

To verify whether SA and JA conferred improved resistance against phylloxera attack to the host plants, exogenous SA and Me-JA were used to pretreat grape roots in vitro before inoculation with nymphs. The nymph survival rate was then investigated to evaluate their repression effects. We found that exogenous applications of both SA and Me-JA inhibited phylloxera parasitism on the host plant (Fig. 4f). More than half of the phylloxera nymphs failed to establish feeding sites on grape roots that had been pretreated with SA compared with the mock control.
To further confirm that $V v W R K Y 46$ is involved in the SA-mediated defense response, the overexpression 35S: VvWRKY46 construct was transformed into wild-type Arabidopsis. Indeed, the expression of the SA-related defense genes was upregulated in the VvWRKY46overexpressing lines (Fig. S5), indicating that phylloxera attack-inducible VvWRKY46 was involved in the SAmediated defense response in plants.

\section{VvHCHIB is transcriptionally activated by VvWRKY46}

As shown by the above results, VvWRKY46 may act as an upstream regulator of SA-induced $P R$ genes in response to phylloxera attack. To determine whether VvWRKY46 regulates phylloxera-inducible $P R$ gene expression, candidate W-box cis-elements in the promoters of $V \nu C H I B, V \nu C H I B 1$, and $V \nu G 1$ were analyzed using the PlantCARE promoter analysis program ${ }^{39}$. Each of the promoter fragments of the detected $P R$ genes contained a putative W-box motif (Fig. 5a); afterward, the indicated promoter sequences were cloned and subjected to $\mathrm{Y} 1 \mathrm{H}$ assays. The reporter construct driven by the endogenous promoter of $V \nu C H I B$ was significantly 


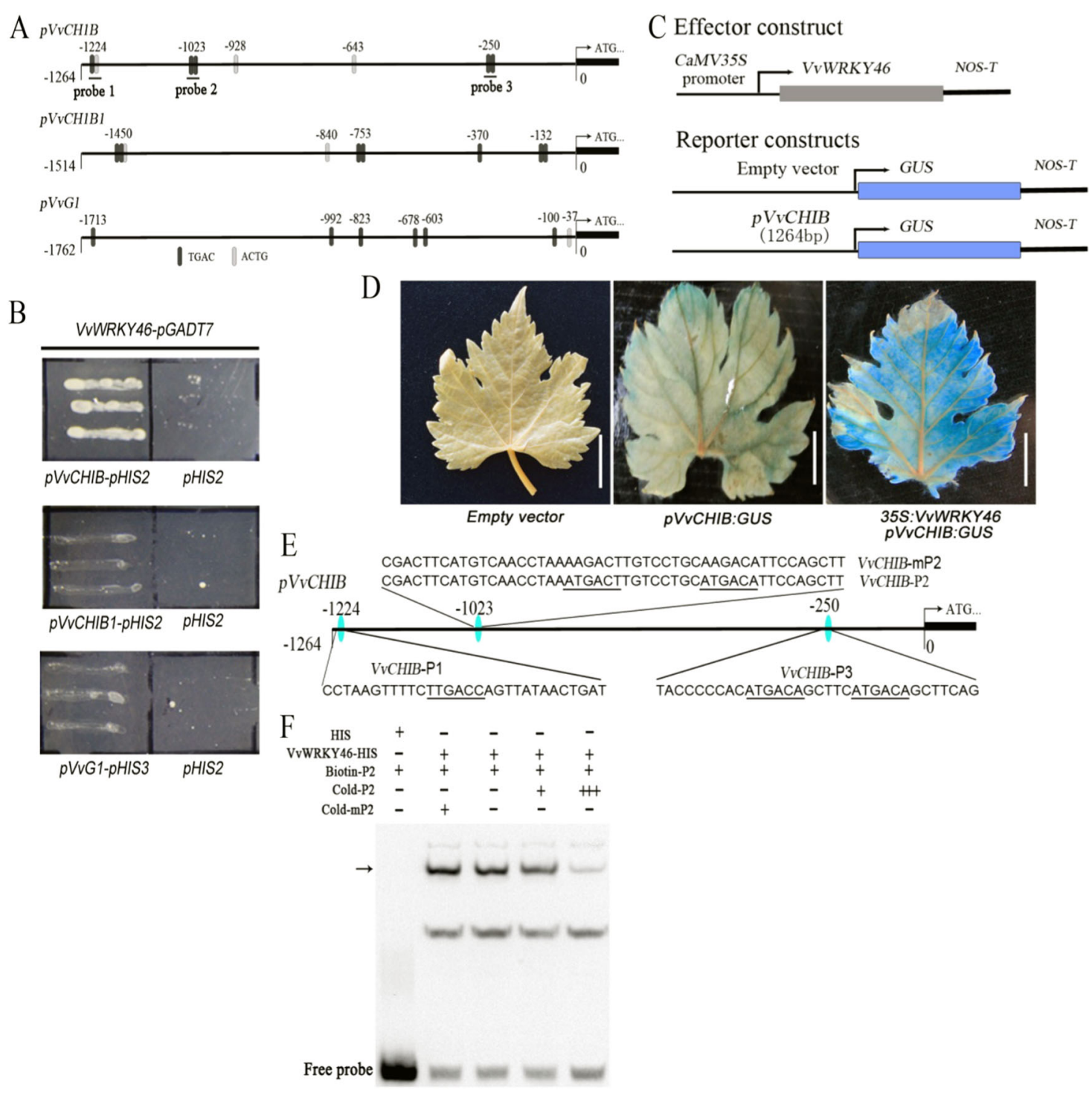

Fig. 5 VvWRKY46 binds directly to the VvCHIB promoter region. a Promoter structure diagrams of $V V C H I B, V_{V} C H I B 1$, and $V_{V G} 1$. The black boxes show W-box motifs with the core sequence $5^{\prime}$-TGAC-3', while the light-gray boxes show the complementary sequence of the W-box motifs (5'ACTG-3'). $\mathbf{b}$ VVWRKY46 transcriptionally activated the promoter of VVCHIB in a Y1H assay. The yeast strain Y187 that harbored pGADT7-VVWRKY46 and pVVCHIB-pHIS2 grew well on a selective plate (SD-T/-L/-H, $20 \mathrm{mM}$ 3-at). c Schematic diagrams of the reporter and effector constructs used for the transient expression assay. $\mathbf{d}$ Histochemical staining of GUS proteins in grapevine leaves. VvWRKY46 transcriptionally activated GUS gene expression driven by the promoter of $V_{V} C H I B$ in grapevine leaves. Each bar was $1 \mathrm{~cm}$. e Three DNA fragments, termed VVCHIB-P1, VVCHIB-P2, and VVCHIB-P3, were used for the EMSAs. All putative W-box motifs are highlighted with black underlines. The core sequence $5^{\prime}$-TGAC-3' of the W-box motif in VVCHIB-P2 was mutated into 5'-AGAC-3', and was termed VVCHIB-mP2. $\mathbf{f}$ The binding activities of the recombinant protein VVWRKY46-HIS to wildtype and mutated probes according to an EMSA. The DNA-protein complex is indicated with a black arrow. Twenty-fold $(+)$ and $100-$ fold $(+++)$ unlabeled VvCHIB-P2 probe was added for competition assays, as well as 20-fold (+) of unlabeled VvCHIB-mP2 probe

activated in yeast cells when co-transformed with VvWRKY46-pGADT7 compared with the blank vector pHIS2 (Fig. 5b). However, VvWRKY46 may exhibit weak binding activity to the promoters of $V \nu C H I B 1$ and $V \nu G 1$ (Fig. 4b). Furthermore, the homologous coexpression assay revealed that $\mathrm{VvWRKY46}$ transcriptionally activated the GUS gene driven by the $V \nu C H I B$ promoter in grape leaves (Fig. $5 \mathrm{c}, \mathrm{d}$ ). To test which putative W-box motif was bound by VvWRKY46, three DNA fragments (VvCHIB-P1, VvCHIB-P2, and VvCHIB-P3) were synthesized and labeled with biotin (Fig. 5a, e). Electrophoretic mobility shift assays (EMSAs) showed that the recombinant protein VvWRKY46-HIS specifically formed a protein-DNA complex with the probe VvCHIB-P2, but did not form a complex with the other two probes in vitro (Fig. 5f; S6A, B). In addition, the 
protein-DNA complex can be competitively inhibited via unlabeled wild-type and mutated probes, again confirming its binding activity.

\section{Overexpression of $V v W R K Y 46$ alleviates the attack of phylloxera on grape roots}

After 14 days of phylloxera infestation, the roots of the phylloxera-susceptible cultivar "Crimson Seedless" and the phylloxera-resistant rootstock 1103P formed nodosities. This finding indicates that the phylloxera successfully infested and developed on the roots. VvWRKY46 and its target gene $V \nu C H I B$ are involved in phylloxera-induced nodosity generation in the susceptible cultivar "Crimson Seedless" (Fig. 6a, b). With respect to the mildly resistant rootstock 1103P, the mRNA level of WRKY46 decreased at the feeding site, while $C H I B$ showed higher levels of transcription than did the control plants (Fig. 6a, b); it is likely that CHIB may be associated with more WRKY46mediated defense regulatory pathways. SA is a key molecular inducer of plant systemic acquired resistance (SAR) against a wide range of plant pathogens, including herbivores. The expression patterns of WRKY46 and its target gene $C H I B$ were detected in the healthy roots of infected plants. Interestingly, both WRKY46 and CHIB responded systemically to phylloxera attack, and their expression was downregulated compared with that in control plants (Fig. 6a, b). In addition, the transcript levels of WRKY46 and CHIB in 1103P were higher than those in "Crimson Seedless" regardless of whether the plants were attacked by phylloxera.

Transgenic roots were obtained by $A$. rhizogenesmediated shoot cutting infection. Fluorescence tests on regenerated roots around the wounds were performed to check which roots were transgenic (Fig. 6c). Real-time RT-PCR confirmed that VvWRKY46 was upregulated in the roots of composite plants and in the marker genes of its downstream target $V \nu C H I B$ and the SA signaling component VvPR1 (Fig. 6d). To determine whether overexpression of $V v W R K Y 46$ resulted in enhanced resistance to phylloxera attack, phylloxera eggs (5 days post oviposition) were inoculated on the roots of line 2 and line 6 composite plants (in which VvWRKY46 was upregulated to different degrees). The numbers of successfully infested nymphs on the transgenic roots were significantly reduced compared with those on the control plants (Fig. 6e). In addition, overexpression of VvWRKY46 caused a retardation of nymph development (Fig. 6f), and the rate of phylloxera development was affected by the expression of $V v W R K Y 46$ in different composite plants; the development was slowest on the 6line composite plants, in which VvWRKY46 was strongly upregulated. Thus, the positive effects of VvWRKY46 in grapevine in defense against phylloxera are strongly confirmed.

\section{Discussion}

Previously, the results of GeneChip microarrays revealed that WRKY transcription factors are involved in phylloxera-grapevine interactions. Phylloxera damage on rootstock $140 \mathrm{Ru}(V$. berlandieri $\times V$. rupestris $)$ significantly induced the expression of three WRKY genes, but not in "Crimson Seedless"15. In this study, VvWRKY46 was identified as a putative defense-related component elicited by phylloxera attack on grapevine roots. A good mechanism by which WRKY46 is involved in the plant defense response to species-specific phylloxera was studied in two grapevine genotypes. WRKY46 is differentially expressed in different grapevine species, exhibits significant susceptibility levels to phylloxera damage, and is associated with SA-mediated plant immune-regulatory networks. These findings suggests that WRKY46 may act as a key regulator and that its expression pattern is closely correlated with host susceptibility.

In general, defense-related transcription factors, such as WRKY and TGA, act downstream of SA-dependent systemic acquired resistance (SAR), which initiates later than the accumulation of the plant defense hormone SA induced by $R$ genes ${ }^{40}$. As described above, WRKY or TGA reprograms the transcript levels of the NPR1 and $P R$ genes downstream of the SA signaling pathway by direct binding activity ${ }^{28,41}$. For the defense response in which WRKY46 is involved, WRKY46 has been shown to contribute to host plant resistance to biotic stresses based on the following observations: (1) pathogen-induced SA accumulation increases the transcript level of WRKY46 (also known as WRKY48 in grape) in Arabidopsis and grapevine $^{42-44}$, and (2) AtWRKY46 can promote SA biosynthesis by transcriptionally upregulating the structural gene PBS3 in Arabidopsis ${ }^{22}$. It is speculated that WRKY46 positively regulates the SA signal transduction pathway induced by plant pathogens and may directly regulate SA metabolism through a feedback loop. However, it is unclear whether the pathogens attack simultaneously or sequentially to trigger SA accumulation and upregulation of WRKY46 or other WRKY genes around the site of infection.

GUS staining and qRT-PCR assays confirmed that mechanical damage resulted in local accumulation of $V \nu W R K Y 46$ mRNA and that the promoter of $V \nu W R K Y 46$ was rapidly and locally transactivated around the wound. Wound-inducible WRKY transcription factors exhibit rapid and transient responses in a short period of time $^{45,46}$. Young nymphs may be looking for the correct feeding site before puncture, and the wound caused by stylet piercing is small and limited. In contrast, WRKY46 was incorrectly regulated by the sucking action of the phylloxera nymphs after inoculation for a long time. In piercing injuries, watery saliva secreted by phloem-feeding 

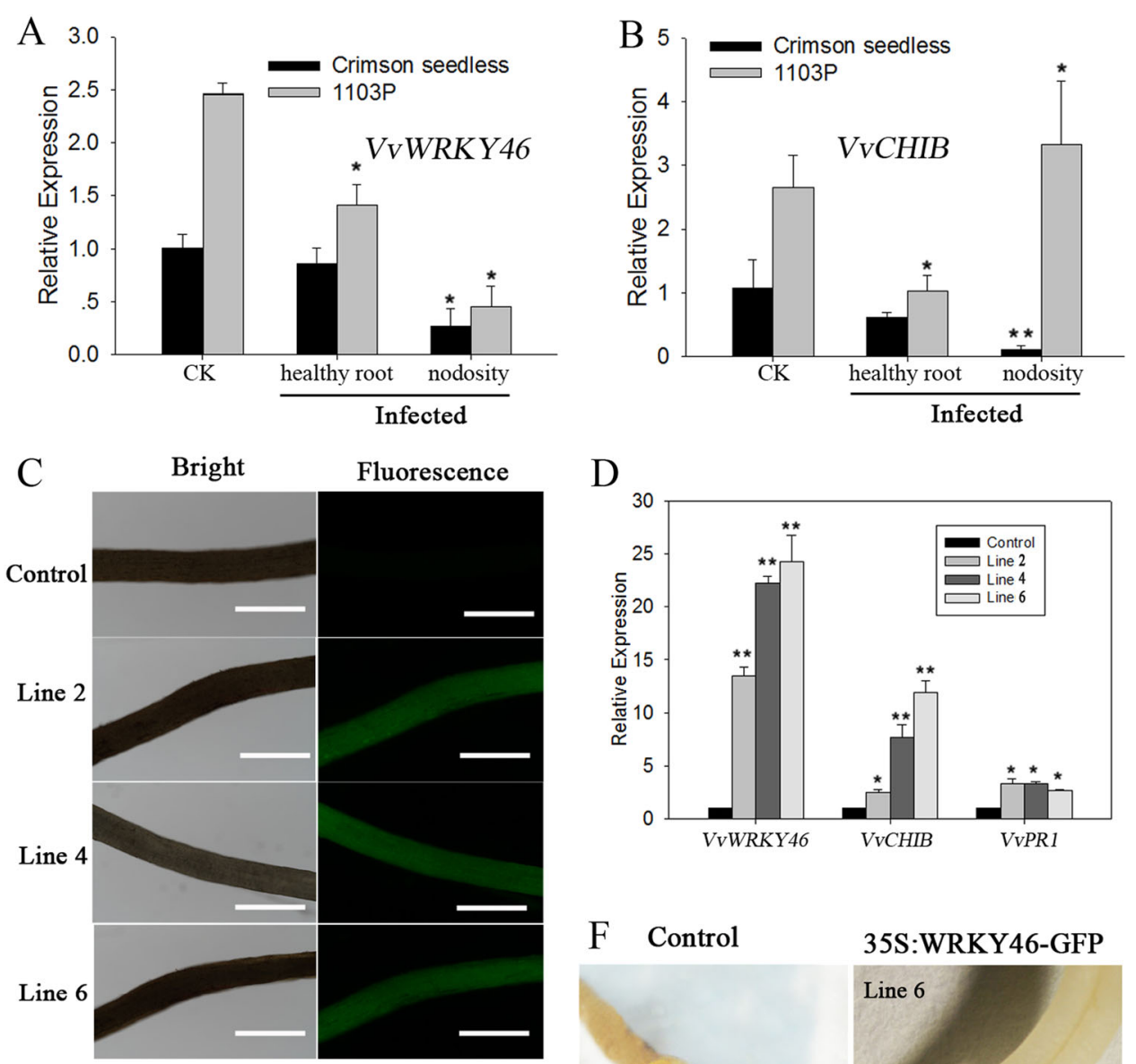

D

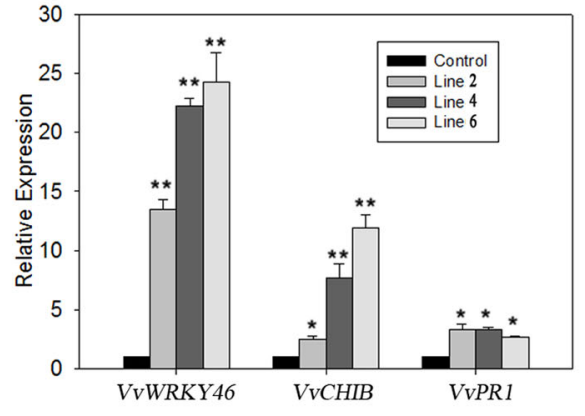

$\mathrm{E}$

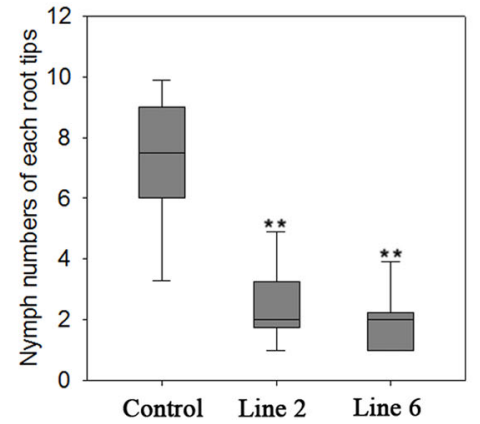

F Control

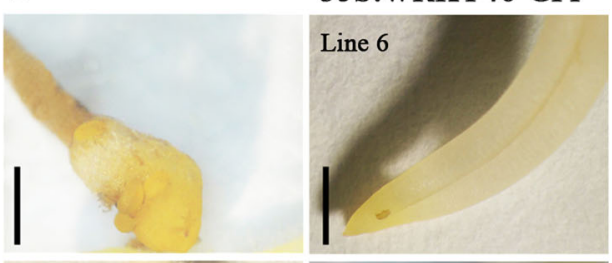

35S:WRKY46-GFP

Line 2

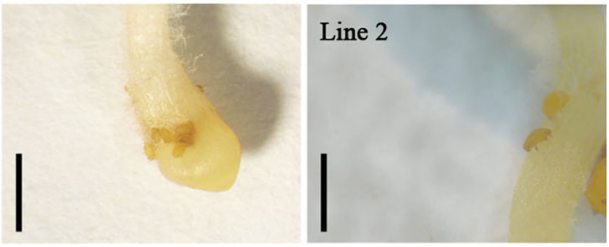

Fig. 6 Overexpression of VvWRKY46 alleviates the attack of phylloxera on grape roots. The mRNA levels of $V W W R K Y 46$ (a) and $V V C H I B$ (b) in infected and noninfected grape roots of "Crimson Seedless" and 1103P after nodosity formation. The gene expression levels were normalized to the noninfected expression levels, which were assigned a value of 1. c Transgenic roots developing on wild-type shoots of "Crimson Seedless" after infection with Agrobacterium rhizogenes and the expression of green fluorescence protein marker in transgenic roots at $480 \mathrm{~nm}$ light. The bars are $50 \mu \mathrm{m}$. d Transcript abundance of VVWRKY46, VVCHIB, and VVPR1 in transgenic roots sampled from separate composite plants. All gene expression levels were normalized to those of the control plant (35S:GFP), which were assigned a value of 1. e The numbers of phylloxera nymphs that successfully fed on grape roots. The black line in each box indicates the mean value, $n>10$. The asterisks indicate significant differences compared with the control plants according to Student's $t$-test, ${ }^{* *} P<0.01$. $\mathbf{f}$ Micrograph of grape root nodosities induced by phylloxera nymphs at 2 weeks post inoculation. Scale bars $=100 \mu \mathrm{m}$

pests greatly promotes the induction of plant defense responses ${ }^{47}$. The different transcript profiles reveal a fundamental difference in defense-related components caused by mechanical damage and insect feeding ${ }^{48}$. It is believed that mechanical wounding and herbivory do not trigger the exact same signaling pathways in plants ${ }^{49}$, although a group of molecular components is involved in the downstream transduction of the two exogenous stimuli described above. Biochemical factors that are related to tissue repair and that immediately accumulate in plant 
cells may preferentially act as signaling molecules in response to mechanical wounding.

According to the canonical binding performance of WRKY transcription factors as previously described ${ }^{37}$, VvWRKY46 specifically bound to the W-box motif $5^{\prime}$ ATGACT- $3^{\prime}$ instead of $5^{\prime}$-ATGACA- $3^{\prime}$ or $5^{\prime}$-TTGACC$3^{\prime}$. The core sequence $5^{\prime}$-TGAC- $3^{\prime}$ is essential for highbinding affinity as well as the $3^{\prime}$ flanking base $\mathrm{T}$. With respect to upregulated genes in transgenic Arabidopsis plants, sequence analyses of their promoters revealed several potential binding sites for VvWRKY46. In particular, the W-box motif 5'-ATGACT-3' bound by VvWRKY46 was identified within the promoters of AtPBS3 and AtPR3, suggesting a putative cascade relationship between WRKY46 and its downstream targets. WRKY46 may have a conserved binding profile to target the PBS3 and PR3 genes in plants, although AtWRKY46 did not reveal the exact binding site of the AtPBS3 promoter $^{22}$.

Time course assays showed that WRKY46 responded to different expression patterns of phylloxera attack in the susceptible "Crimson Seedless" and the resistant rootstock 1103P. Uehara et al. ${ }^{50}$ isolated and characterized several differentially expressed genes in compatible and incompatible interactions between tomato and parasitic nematodes. Due to their genomic background, defenserelated components may play different roles in pathogenic attacks $^{51}$. The transcript abundance of WRKY46 showed a late but sustained increase in the 1103P rootstock compared with the susceptible "Crimson Seedless". Furthermore, WRKY46 has a higher background expression in uninfected 1103P roots than in "Crimson Seedless" and healthy roots and nodosities of infected plants. We hypothesized that $1103 \mathrm{P}$ specifically induces upstream WRKY46 upregulation at the transcriptional level to initiate downstream functional genes. Indeed, the $V v C H I B$ gene, which encodes chitinase and protects against chitincontaining pathogens ${ }^{52}$, appears to be a direct downstream target of $V v W R K Y 46$ and exhibits a similar expression pattern, except with respect to 1103P nodosities. It cannot be ruled out that $V \nu C H I B$ may be regulated transcriptionally by other defense-related networks responsible for phylloxera damage ${ }^{15}$. Interestingly, both VvWRKY46 and VvCHIB are associated with a systemic defense response induced by phylloxera attack. SA or other molecules may play pivotal roles in the signaling of the entire host plant.

\section{Conclusions}

VvWRKY46 is characterized as a nuclear localization transcription factor responsible for compatible and incompatible interactions between phylloxera and grapevine host plants. Phylloxera attack triggered a defense response that was closely related to the SA-mediated immune regulatory network. $V \nu C H I B$ was confirmed to be the downstream target of $V v W R K Y 46$ by direct protein-DNA interaction. Overexpression of $V v W R K Y 46$ significantly reduced the invasive nature of phylloxera attack and slowed the development of nymphs in composite grape plants. WRKY46 exhibits a higher transcript abundance in 1103P than in "Crimson Seedless", regardless of whether the plants are infected with phylloxera, which means species-specific effects occur in terms of defense responses against obligate pests.

\section{Funding}

This research was supported by the National Natural Science Foundation of China in 2012 (31201609).

\section{Author details \\ ${ }^{1}$ State Key Laboratory of Crop Biology, Key Laboratory of Biology and Genetic Improvement of Horticultural Crops (Huang-Huai Region, Ministry of \\ Agriculture), College of Horticulture Science and Engineering, Shandong Agricultural University, Tai-an 271000 Shandong, China. ${ }^{2}$ Key Laboratory of Optoelectronic Devices and Systems of Ministry of Education and Guangdong Province, College of Optoelectronic Engineering, Shenzhen University, Shen- zhen 518060 Guangdong, China. ${ }^{3}$ Guangdong Provincial Key Laboratory for Plant Epigenetics, College of Life Sciences and Oceanography, Shenzhen University, Shen-zhen 518060 Guangdong, China. ${ }^{4}$ College of Biological and Enology Engineering, Taishan University, Tai-an 271000 Shandong, China}

\section{Conflict of interest}

The authors declare that they have no conflict of interest.

Supplementary Information accompanies this paper at (https://doi.org/ 10.1038/s41438-019-0185-8).

Received: 18 May 2019 Revised: 8 July 2019 Accepted: 16 July 2019 Published online: 01 September 2019

\section{References}

1. Chisholm, S. T., Coaker, G., Day, B. \& Staskawicz, B. J. Host-microbe interactions: shaping the evolution of the plant immune response. Cell 124, 803-814 (2006).

2. Jones, J. D. \& Dangl, J. L. The plant immune system. Nature 444, 323-329 (2006).

3. Tsuda, K., Katagiri, F., Parker, J. E. \& Ellis, J. G. Comparing signaling mechanisms engaged in pattern-triggered \& effector-triggered immunity. Curr. Opin. Plant Biol. 13, 459-465 (2010).

4. Zarate, S. I., Kempema, L. A. \& Walling, L. L. Silverleaf whitefly induces salicylic acid defenses and suppresses effectual jasmonic acid defenses. Plant Physiol. 143, 866-875 (2007).

5. Kawazu, K. et al. Different expression profiles of jasmonic acid and salicylic acid inducible genes in the tomato plant against herbivores with various feeding modes. Arthropod-Plant Interact. 10, 87-87 (2016).

6. Liu, Y. \& Zhang, S. Phosphorylation of 1-aminocyclopropane-1-carboxylic acid synthase by MPK6, a stress-responsive mitogen-activated protein kinase, induces ethylene biosynthesis in Arabidopsis. Plant Cell 16, 3386-3399 (2004).

7. Glazebrook, J. Contrasting mechanisms of defense against biotrophic and necrotrophic pathogens. Annu. Rev. Phytopathol. 43, 205-227 (2005).

8. Lin, J. et al. Overexpression of a soybean salicylic acid methyltransferase gene confers resistance to soybean cyst nematode. Plant Biotechnol. J. 11, 1135-1145 (2013).

9. Leitner, M. \& Boland, W. A. Direct and indirect defences induced by piercingsucking and chewing herbivores in Medicago truncatula. New Phytol. 167, 597-606 (2005)

10. An, C. \& Mou, Z. Salicylic acid and its function in plant immunity. J. Integr. Plant Biol. 53, 412-428 (2011). 
11. Claverie, M. et al. The Ma gene for complete-spectrum resistance to Meloidogyne species in Prunus is a TNL with a huge repeated C-terminal post-LRR region. Plant Physiol. 156, 779-792 (2011).

12. Du, B. et al. Identification and characterization of Bph14, a gene conferring resistance to brown plant hopper in rice. Proc. Natl Acad. Sci. USA 106, 22163-22168 (2009)

13. Branch, C., Hwang, C. F., Navarre, D. A. \& Williamson, V. M. Salicylic acid is part of the Mi-1-mediated defense response to root-knot nematode in tomato. Mol. Plant Microbe. Inter. 17, 351-356 (2004).

14. Molinari, S., Fanelli, E. \& Leonetti, P. Expression of tomato salicylic acid (SA)-responsive pathogenesis-related genes in Mi-1-mediated and SAinduced resistance to root-knot nematodes. Mol. Plant Pathol. 15, 255-264 (2014).

15. Du, Y. P., Jiang, E. S., Wang, F. P., Zhang, S. Z. \& Zhai, H. Gene expression profiling of rootstock '140Ru' and Vitis vinifera L. CV. 'Crimson Seedless' grape roots infected with grape phylloxera. Plant Growth Regul. 73, 1-8 (2014).

16. Elhamahmy, M. A. M., Mahmoud, M. F. \& Bayoumi, T. Y. The effect of applying exogenous salicylic acid on aphid infection and its influence on histophysiological traits and thermal imaging of canola. Cercet. Agron. Mold. 49, 67-85 (2016)

17. Eulgem, T. \& Somssich, I. E. Networks of WRKY transcription factors in defense signaling. Curr. Opin. Plant Biol. 10, 366-371 (2007).

18. Wang, $\mathrm{H}$. et al. Overexpression of rice WRKY89 enhances ultraviolet B tolerance and disease resistance in rice plants. Plant Mol. Biol. 65, 799-815 (2007).

19. Li, P. et al. The over-expression of a chrysanthemum WRKY transcription factor enhances aphid resistance. Plant Physiol. Biochem. 95, 26-34 (2015).

20. Wim, G. et al. A role for AtWRKY23 in feeding site establishment of plantparasitic nematodes. Plant Physiol. 148, 358-368 (2008).

21. Chinnapandi, B., Bucki, P. \& Braun, S. M. SIWRKY45, nematode-responsive tomato WRKY gene, enhances susceptibility to the root knot nematode; $M$. javanica infection. Plant Signal. Behav. 12, e1356530 (2017).

22. Verk, M. C. V., Bol, J. F. \& Linthorst, H. J. WRKY transcription factors involved in activation of SA biosynthesis genes. BMC Plant Biol. 11, 89-89 (2011).

23. Petersen, K., Fiil, B. K., Mundy, J. \& Petersen, M. Downstream targets of WRKY33. Plant Signal Behav. 3, 1033-1034 (2008).

24. Qiu, J. L. et al. Arabidopsis MAP kinase 4 regulates gene expression through transcription factor release in the nucleus. Embo J. 27, 2214-2221 (2014).

25. Mukhtar, M. S., Nishimura, M. T. \& Dangl, J. NPR1 in plant defense: it's not over 'til it's turned over. Cell 137, 804-806 (2009).

26. Yu, D. \& Chen, Z. Evidence for an important role of WRKY DNA binding proteins in the regulation of NPR1 gene expression. Plant Cell 13, 1527-1540 (2001).

27. Wang, D., Amornsiripanitch, N. \& Dong, X. A genomic approach to identify regulatory nodes in the transcriptional network of systemic acquired resistance in plants. Plos Pathog. 2, e123 (2006).

28. Kim, K. C., Lai, Z., Fan, B. \& Chen, Z. Arabidopsis WRKY38 and WRKY62 transcription factors interact with histone deacetylase 19 in basal defense. Plant Cell 20, 2357-2371 (2008).

29. Verk, M. C. V., Neeleman, L., Bol, J. F. \& Linthorst, H. J. M. Tobacco transcription factor NtWRKY12 interacts with TGA2.2 in vitro and in vivo. Front Plant Sci. 2, 1085-1091 (2011).

30. Raman, A., Beiderbeck, R. \& Herth, W. Early subcellular responses of susceptible and resistant Vitis taxa to feeding by grape phylloxera Daktulosphaira vitifoliae. Bot. Helv. 119, 31-39 (2009).

31. Dietrich, A., Wolf, T., Eimert, K. \& Schröder, M. B. Activation of gene expression during hypersensitive response (HR) induced by auxin in the grapevine rootstock cultivar 'Börner'. Vitis. J. Grapevine Res. 49, 15-21 (2010).
32. Blank, L., Wolf, T., Eimert, K. \& Schröder, M. Differential gene expression during hypersensitive response in -resistant rootstock 'Börner' using custom oligonucleotide arrays. J. Plant Interact. 4, 261-269 (2009).

33. Granett, J., Goheen, A. C., Lider, L. A. \& White, J. J. Evaluation of grape rootstocks for resistance to type $\mathrm{A}$ and type B grape phylloxera. Am. J. Enol. Vitic. 38, 298-300 (1987).

34. Kellow, A. V., Corrie, A. M. \& Heeswjck, R. Surface sterilisation of phylloxera eggs for investigating grapevine-phylloxera interactions in tissue culture. Australian J. Grape and Wine Res. 5, 27-28 (1999).

35. Gambino, G., Perrone, I. \& Gribaudo, I. (2010) A rapid and effective method for RNA extraction from different tissues of grapevine and other woody plants. Phytochem Anal. 19, 520-525 (1999).

36. Du, Y. P., Wang, Z. S., Sun, Q. H., Zhai, H. \& Wang, Z. Y. Evaluating resistance of some grape varieties and rootstocks to grape phylloxera (in chanese). Acta Èntomol. Sin. 51, 33-39 (2008).

37. Eulgem, T., Rushton, P. J., Robatzek, S. \& Somssich, I. E. The WRKY superfamily of plant transcription factors. Trends Plant Sci. 5, 199-206 (2000).

38. Nabity, P. D., Haus, M. J., Berenbaum, M. R. \& Delucia, E. H. Leaf-galling phylloxera on grapes reprograms host metabolism and morphology. Proc Natl Acad Sci USA. Proc. Natl Acad. Sci. USA 110, 16663-16668 (2013).

39. Lescot, M. et al. PlantCARE, a database of plant cis-acting regulatory elements and a portal to tools for in silico analysis of promoter sequences. Nucleic Acids Res. 30, 325-327 (2002).

40. Shah, J. The salicylic acid loop in plant defense. Curr. Opin. Plant Biol. 6 365-371 (2003).

41. Kim, H. S. \& Delaney, T. P. Over-expression of TGA5, which encodes a bZIP transcription factor that interacts with NIM1/NPR1, confers SAR-independent resistance in Arabidopsis thaliana to Peronospora parasitica. Plant J. 32 , 151-163 (2010).

42. Hu, Y., Dong, Q. \& Yu, D. Arabidopsis WRKY46 coordinates with WRKY70 and WRKY53 in basal resistance against pathogen Pseudomonas syringae. Plant Sci. 185-6, 288-297 (2012).

43. Guo, C. et al. Evolution and expression analysis of the grape (Vitis vinifera L.) WRKY gene family. J. Exp. Bot. 65, 1513-1528 (2014).

44. Zhao, J. et al. Over-expression of a grape WRKY transcription factor gene, VIWRKY48, in Arabidopsis thaliana increases disease resistance and drought stress tolerance. Plant Cell Tissue Organ Cult. 132, 359-370 (2018).

45. Park, C. J. et al. A hot pepper gene encoding WRKY transcription factor is induced during hypersensitive response to Tobacco mosaic virus and Xanthomonas campestris. Planta 223, 168-179 (2006).

46. Zhang, Q., Zhu, J., Ni, Y., Cai, Y. \& Zhang, Z. Expression profiling of HbWRKY1, an ethephon-induced WRKY gene in latex from Hevea brasiliensis in responding to wounding and drought. Trees 26, 587-595 (2012).

47. Felton, G. W. \& Tumlinson, J. H. Plant-insect dialogs: complex interactions at the plant-insect interface. Curr. Opin. Plant Biol. 11, 457-463 (2008).

48. Reymond, P., Weber, H., Damond, M. \& Farmer, E. E. Differential gene expression in response to mechanical wounding and insect feeding in Arabidopsis. Plant Cell 12, 707-719 (2000).

49. Mithöfer, A. \& Boland, W. Recognition of herbivory-associated molecular patterns. Plant Physiol. 146, 825-831 (2008).

50. Uehara, T., Sugiyama, S., Matsuura, H., Arie, T. \& Masuta, C. Resistant and susceptible responses in tomato to cyst nematode are differentially regulated by salicylic acid. Plant Cell Physiol. 51, 1524-1536 (2010).

51. Kumari, C., Dutta, T. K., Banakar, P. \& Rao, U. Comparing the defence-related gene expression changes upon root-knot nematode attack in susceptible versus resistant cultivars of rice. Sci. Rep. 6, 22846 (2016).

52. Hamamouch, N., Li, C., Seo, P. J., Park, C. M. \& Davis, E. L. Expression of Arabidopsis pathogenesis-related genes during nematode infection. Mol. Plant Pathol. 12, 355-364 (2011). 